\title{
Urgent Splenectomy after Partial Splenic Embolization in Liver-Transplanted Patient: A Case Report
}

\author{
Jorge Herrador Benito, ${ }^{1}$ M. G. Zunzarren, ${ }^{1}$ T. Pozancos de Simón, ${ }^{1}$ L. Tortolero, ${ }^{1}$ \\ R. Latorre Fragua, ${ }^{1}$ J. Nuño, ${ }^{2}$ and E. Lobo ${ }^{1}$ \\ ${ }^{1}$ Department of General and Digestive Surgery, Ramón y Cajal Hospital, Cra. Colmenar Km 9, 1, 28034 Madrid, Spain \\ ${ }^{2}$ Liver Transplantation Unit, Department of General and Digestive Surgery, Ramón y Cajal Hospital, Cra. Colmenar Km 9 , \\ 1, 28034 Madrid, Spain
}

Correspondence should be addressed to Jorge Herrador Benito, jorge.herrador@gmail.com

Received 2 September 2012; Accepted 16 October 2012

Academic Editors: C. F. Classen, C. Costa, and J. Jazbec

Copyright (C) 2012 Jorge Herrador Benito et al. This is an open access article distributed under the Creative Commons Attribution License, which permits unrestricted use, distribution, and reproduction in any medium, provided the original work is properly cited.

We describe a 51-year-old-male. Three months after liver transplantation due to hepatitis C virus (HCV) hepatopathy, an HCV relapse was detected, and partial splenic embolization (PSE) was performed prior to antiviral treatment. Eleven days after PSE emergency splenectomy was performed due to the development of a splenic abscess, which is a rare but severe complication of PSE. Between May 2002 and March 2012, 18 PSEs have been performed in transplant patients in our centre. The patient presented here is the only case of splenic abscess and the only one who has needed surgery after complications of PSE.

\section{Introduction}

Approximately $20-30 \%$ of patients who receive a liver transplant due to hepatitis c virus hepatopathy develop cirrhosis before 5 years, and up to $14 \%$ experience a serious relapse in the first year after transplantation [1-3]. Hypersplenism in these patients results in decreased platelet levels, which does not allow treatment with pegylated interferon (PegIFN) and ribavirin because these drugs are associated with hematological toxicity, especially thrombocytopenia in the case of Peg-IFN. Partial splenic embolization (PSE) is an effective alternative to splenectomy in these patients to correct platelet levels if antiviral treatment is necessary [47].

\section{Case Report}

We describe a 51-year-old male who received a liver transplant secondary to HCV liver cirrhosis. Immunosuppression received was Tacrolimus $6 \mathrm{mg} / 12 \mathrm{~h}$ and Methylprednisolone $20 \mathrm{mg}$. During the postoperative period the patient presented with right pleural effusion, mild renal failure, and mild preservation injury with minimal graft dysfunction compatible with preservation cholestasis.

Three months after liver transplantation a serious HCV relapse was detected by the presence of serious lobular hepatitis in a liver biopsy, with a total bilirubin of $6 \mathrm{mg} / \mathrm{dL}, \mathrm{HCV}$ viral load of 100,000,000 UI/mL, and hyperglycemia associated with the relapse. Platelet levels were 44,600 cells $/ \mathrm{mm}^{3}$ (see Table 1).

To correct the blood platelet levels prior to antiviral treatment, splenic embolization was performed for approximately $90 \%$ of the parenchyma, preserving only a central hilar area and another area in the upper pole (see Figure 1). The technique was distal superselective catheterization of the splenic artery through the femoral artery with the injection of particles of polyvinyl alcohol in solution with penicillin, gentamicin, and iodinated contrast. The patient was discharged 6 days after embolization, after a period of time without complications.

Three days later, the patient arrived at the emergency department with a fever of $38.5^{\circ} \mathrm{C}$ and diffuse abdominal pain, primarily in the left upper quadrant. An urgent CT scan showed free fluid in the pelvis and paracolic gutters, 
TABLE 1: The evolution of blood platelet levels.

\begin{tabular}{lc}
\hline & Platelets (cells/mm $\left.{ }^{3}\right)$ \\
\hline Prembolization levels (70 days post-transplant) & 44,600 \\
Postembolization levels (15 days post-PSE) & 318,000 \\
Postsplenectomy (38 days after splenectomy) & 466,000 \\
\hline
\end{tabular}

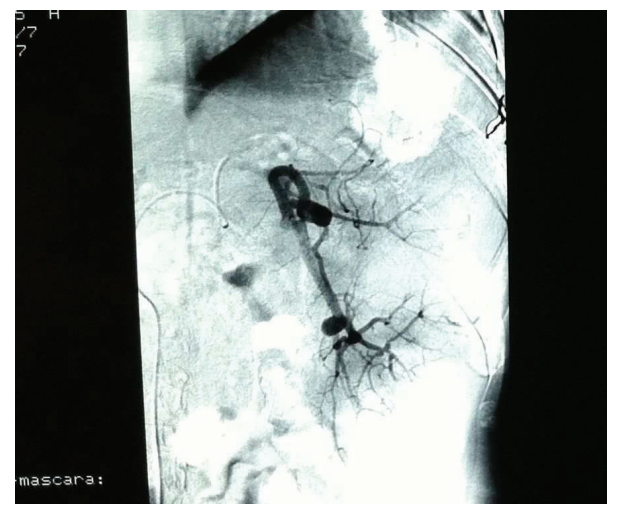

FIGURE 1: Splenic arteriography.

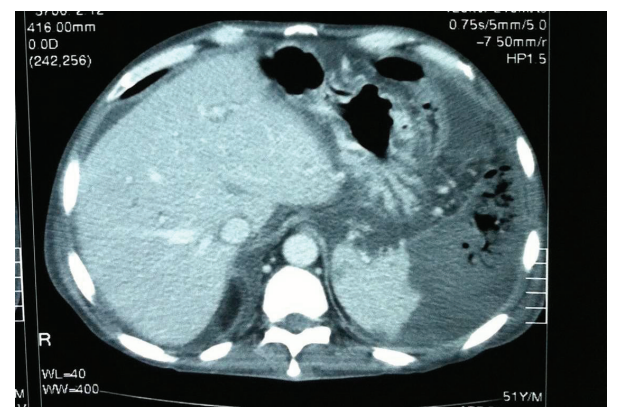

Figure 2: CT scan.

with uptake of contrast medium in the peritoneum. The spleen was enlarged with gas bubbles compatible with the embolization.

We decided to initiate empiric antibiotic and antimycotic treatment (meropenem, tobramycin, and fluconazole). Over the following days, the clinical course included torpidity, development of renal failure, leukocytosis above 30,000, and persisting malaise with abdominal pain and fever. At all times the patient was hemodynamically stable with no need for vasoactive drugs and without respiratory support. Bacteroides fragilis was isolated in blood culture. Eleven days after admission, a new CT scan showed multiple splenic collections of gas compatible with a splenic abscess secondary to the PSE. In addition, adjacent hemoperitoneum was observed, and the splenic capsule was ruptured (Figure 2).

Emergency surgery found roughly 3.5 liters of reddishbrown peritoneal fluid. Splenectomy was performed and blood products transfused. After 3 days in the ICU, the patient required a prolonged stay and was discharged at postoperative day 40. Regarding the evolution of graft function from the time of embolization, the analytical figures were gradually normalized, reaching the following levels: $\mathrm{AST}=43, \mathrm{ALT}=16, \mathrm{FA}=202$, and GGT $=296$.

\section{Discussion}

The morbidity of PSE is well known. Almost 100\% of patients develop the so-called "postembolization syndrome" (fever, abdominal pain, nausea) caused by splenic infarction and the release of proinflammatory cytokines. Other "minor" complications were pleural effusion, the development of neutrophilic ascites, which is usually transient and responsive to diuretic therapy, and splenic or portal thrombosis. The most serious complications are the development of splenic abscess and distal pancreatitis. Splenic abscess formation is not a infrequent and severe complication of PSE that occurs in 5-15\% of PSE. Like other complications, abscess formation is related to the volume of parenchyma that is embolized, occurring with volumes greater than $70 \%$. The treatment of choice is urgent splenectomy; though medical treatment support, antibiotics, and occasional percutaneous drainage can be attempted in patients with major functional impairment, it often provides worse results [8$10]$.

Between May 2002 and March 2012, 74 PSEs have been performed in our centre, including 18 procedures in transplant patients. The patient presented here is the only case of splenic abscess, and the only one who has required surgery after complications of PSE, assuming $1.4 \%$ for total PSE and 5.6\% among transplant patients.

\section{Conflict of Interests}

The authors state that they have no conflict of interests.

\section{References}

[1] R. Bárcena, A. Moreno, J. R. Foruny et al., "Partial splenic embolization and peg-IFN plus RBV in liver transplanted patients with hepatitis $\mathrm{C}$ recurrence: safety, efficacy and longterm outcome," Clinical Transplantation, vol. 24, no. 3, pp. 366-374, 2010.

[2] E. Otón, R. Bárcena, J. M. Moreno-Planas et al., "Hepatitis $\mathrm{C}$ recurrence after liver transplantation: viral and histologic response to full-dose peg-interferon and ribavirin," American Journal of Transplantation, vol. 6, no. 10, pp. 2348-2355, 2006.

[3] I. Fernández, J. C. Meneu, F. Colina et al., "Clinical and histological efficacy of pegylated interferon and ribavirin therapy of recurrent hepatitis C after liver transplantation," Liver Transplantation, vol. 12, no. 12, pp. 1805-1812, 2006.

[4] B. Sangro, I. Bilbao, I. Herrero et al., "Partial splenic embolization for the treatment of hypersplenism in cirrhosis," Hepatology, vol. 18, no. 2, pp. 309-314, 1993. 
[5] M. A. Amin, M. M. El Gendy, I. E. Dawoud, A. Shoma, A. M. Negm, and T. A. Amer, "Partial splenic embolization versus splenectomy for the management of hypersplenism in cirrhotic patients," World Journal of Surgery, vol. 33, no. 8, pp. 1702-1710, 2009.

[6] M. Takahara, Y. Miyake, H. Miyatake et al., "Partial splenic embolization facilitates the adherence to peginterferon in chronic hepatitis $\mathrm{C}$ with thrombocytopenia," Internal Medicine, vol. 50, no. 22, pp. 2731-2736, 2011.

[7] N. Sohara, H. Takagi, S. Kakizaki, K. Sato, and M. Mori, "The use of partial splenic artery embolization made it possible to administer interferon and ribavirin therapy in a liver transplant patient with fibrosing cholestatic hepatitis C complicated with thrombocytopenia," Transplant International, vol. 19, no. 3, pp. 255-257, 2006.

[8] H. Yoshida, Y. Mamada, N. Taniai, and T. Tajiri, "Partial splenic embolization," Hepatology Research, vol. 38, no. 3, pp. 225-233, 2008.

[9] J. R. Foruny, R. Bárcena, A. Moreno et al., "Benefit of pegylated interferon- $\alpha-2 \mathrm{a} /$ ribavirin in a patient with common variable immunodeficiency and hepatitis $\mathrm{C}$ virus cirrhosis after liver transplantation and splenic embolization," Transplantation, vol. 82, no. 2, pp. 289-290, 2006.

[10] A. Petermann, P. Chabrot, L. Cassagnes et al., "Hypersplenism due to portal hypertension: retrospective evaluation of 17 patients treated by splenic embolization," Diagnostic and Interventional Imaging, vol. 93, no. 1, pp. 30-36, 2012. 


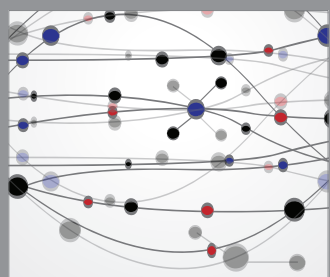

The Scientific World Journal
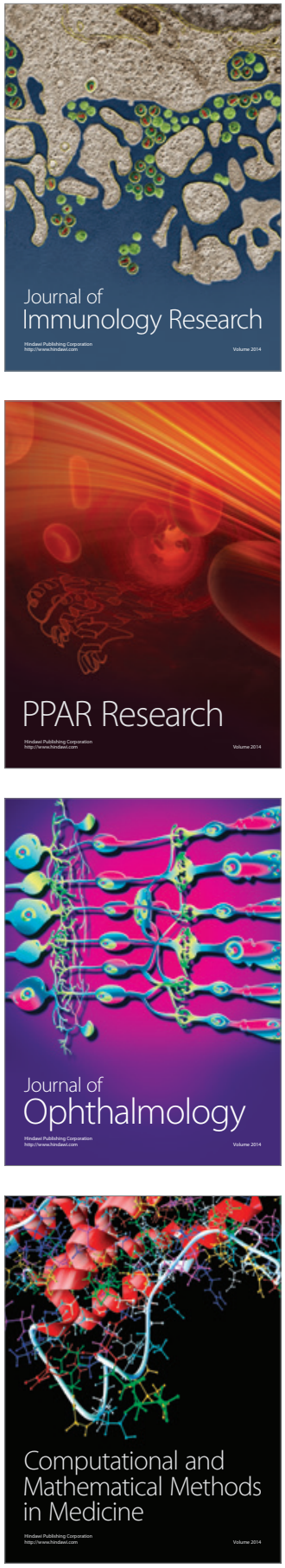

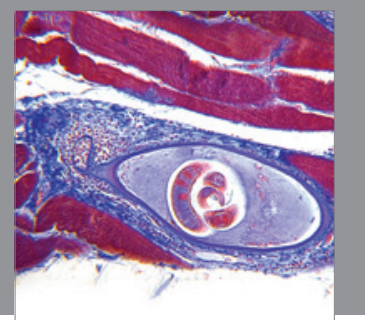

Gastroenterology

Research and Practice
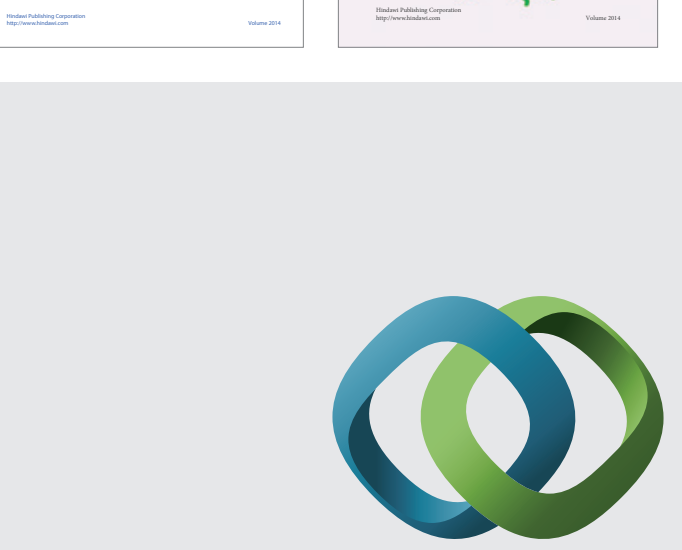

\section{Hindawi}

Submit your manuscripts at

http://www.hindawi.com
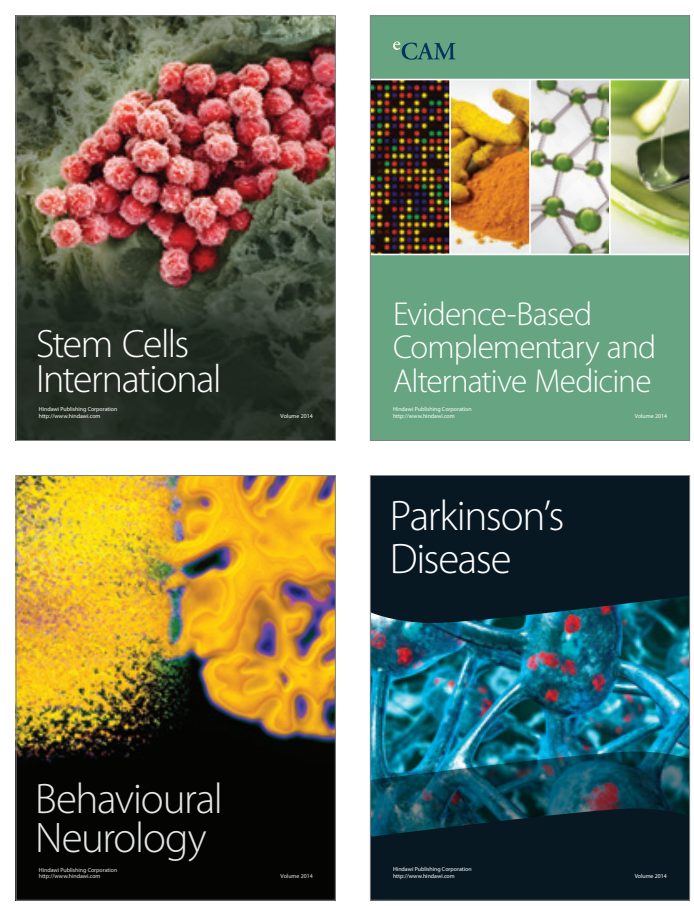

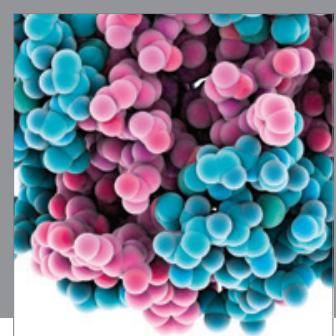

Journal of
Diabetes Research

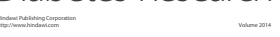

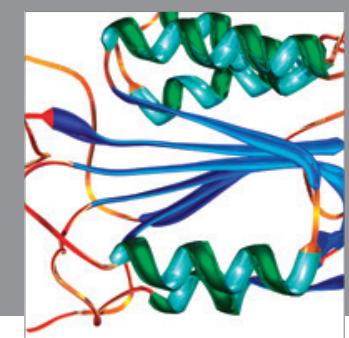

Disease Markers
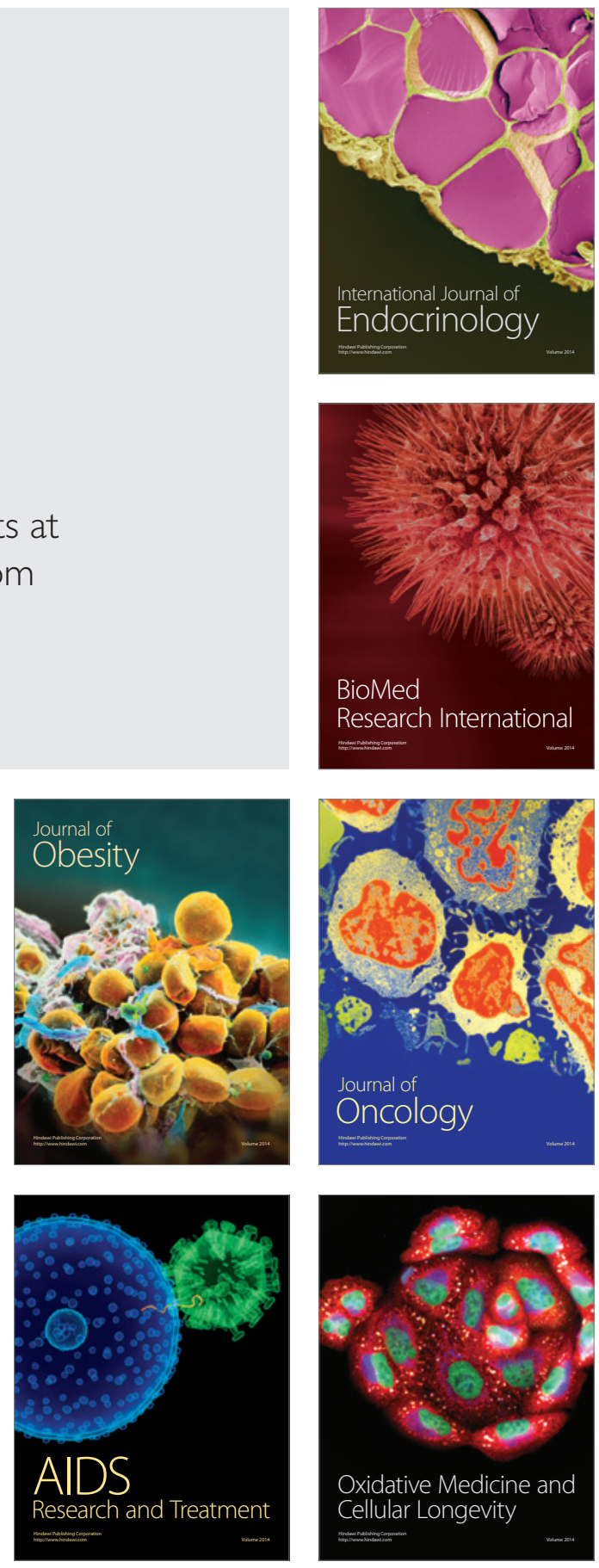